\title{
Особенности сосудисто-тромбоцитарного гемостаза на разных сроках физиологической беременности
}

\author{
А. П. Момот, А.М. Н., профр. ${ }^{1,2}$, И. А. Тараненко, К.М.Н. ${ }^{1,2}$; А. А. Трухина ${ }^{3}$; В. В. Романов, К.М.Н. ${ }^{4}$ \\ 'А^тайский филиал ФГБУ «Гематологический научный центр» МинзАрава России, г. Барнау^ \\ 2ГБОУ ВПО «ААтайский госуАарственный меАицинский университет» МинзАрава России, г. БарнауА \\ ЗКГБУЗ «Краевая КАиническая больница», г. Барнаул \\ ${ }^{4} О О О$ «Инвитро-Сибиры», г. Новосибирск
}

\section{Features of vascular-platelet hemostasis for various periods of physiological pregnancy \\ A.P. Momot',2, I. A. Taranenko 1,2, D. A. Truhina ${ }^{3}$, V. V. Romanov ${ }^{4}$ \\ 'Altai branch of Hematology Research Center, ${ }^{2}$ Altai State Medical University, ${ }^{3}$ Krai Clinical Hospital (Barnaul, Russia), ${ }^{4}$ Invitro-Siberia (Novosibirsk, Russia)}

Резюме

В статье приводятся Аопустимые Аиапазоны значений агрегации тромбоцитов, активности и количества фактора ВимлебранАа и метамлопротиназы ADAMTS-13 при физиологически протекающей беременности. Полученные Аанные уточняют механизмы активации тромбоцитов и могут быть использованы в качестве ориентировочных значений при исслеАования системы гемостаза у беременных женщин и формирования групп риска по кровотечениям и тромбозам.

КАючевые слова: агрегация тромбоцитов, фактор Вимлебранда, метаммопротеиназа ADAMTS-13, физиологически протекающая беременность.
Summary

The article presents the allowable ranges of platelet aggregation, activity and the amount of von Willebrand factor and metalloproteinase ADAMTS-13 in physiological pregnancy. The obtained data clarifies the mechanisms of platelet activation and can be used as indicative values for the study of the hemostatic system in pregnant women and for the formation of groups at risk for bleeding and thrombosis.

Key words: platelet aggregation, von Willebrand factor, ADAMTS-13 metalloproteinase, physiological pregnancy.

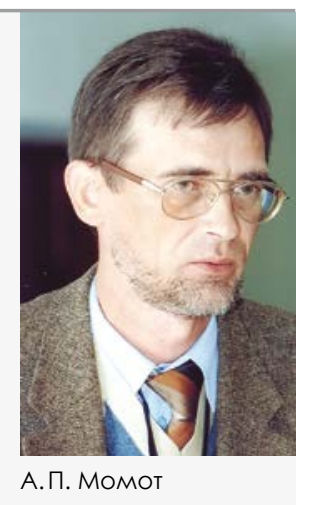

$\mathrm{B}$ соответствии с современными представлениями физиологически протекающая беременность представляет собой процесс, сопровождающийся формированием особых механизмов регуляции жизнедеятельности и меняющегося во времени баланса гемостатических реакций. Имплантация, инвазия трофобласта и дальнейшее успешное функционирование плаценты описаны в последние годы как результат эндотелиально-гемостазиологических взаимодействий со сложной регуляцией [1-4]. Она ассоциируется с прогрессирующей во времени тромбогенностью, формируемой организмом матери для снижения кровопотери в родах [5, 6]. В связи с этим вынашивание беременности и послеродовой период определены в качестве доказанных факторов риска развития венозных тромбозов и тромбоэмболии легочной артерии с частотой в 4-50 раз выше по сравнению с небеременными женщинами. Многие виды патологии беременности (выкиды- ши, синдром задержки внутриутробного развития плода, преждевременные роды и др.) связываются с нарушениями в системе гемостаза. При этом активация свертывания крови может быть критична для развития плода в связи с нарушениями микроциркуляции, маточного и фетоплацентарного кровотока $[7,8]$, а снижение свертывающих свойств крови способно приводить к маточным кровотечениям - нередкому явлению для всех этапов беременности, угрожающему жизни женщины и ребенка при кровопотере свыше 1,5 \% от массы тела роженицы [9-11].

Парадоксальность проблемы состоит в том, что исследованию системы гемостаза придается большое значение при ведении беременности и предупреждении ее осложнений, однако границы нормы и патологии на различных сроках гестации остаются недоступными для реальной лабораторной практики. Имеются публикации, касающиеся нормативных значениий тех или иных по- казателей системы гемостаза при физиологической беременности [6, 12-16]. Однако исследований, посвященных комплексной оценке сосудисто-тромбоцитарного гемостаза — тромбоцитов, фактора Виллебранда (ФВ), металлопротеиназы ADAMTS-13, тромбоцитарного фактора 4 (ПФ4), тромбомодулина, эндотелина-1 в крови в разные сроки беременности ранее не проводилось. Полагаем, что осуществление работ в этом направлении имеет важное значение не только для «вооружения» клинической практики нормативными данными для формирования групп риска по тяжелым кровотечениям и тромбозам, но позволит описать ранее неизвестные механизмы уникального гемостатического баланса на протяжении физиологически протекающей беременности.

В основу настоящей работы вошли данные о 301 женщине, обследованной в женских консультациях и родильном доме № 2 г. Барнаула. Исследования выполнялись в лаборатории 
Таблица

Аопустимый интервал значений количества тромбоцитов в крови, ×10\%/А

\begin{tabular}{|c|c|c|c|c|}
\hline $\begin{array}{c}\text { Этап } \\
\text { обслеАования }\end{array}$ & Срок беременности & Me & $x$ & $\begin{array}{c}\text { Референтный интервал } \\
(2,5-97,5 \% \text { o })\end{array}$ \\
\hline 1 & Вне беременности ( $n=48)$ & 239,00 & 233,69 & $162,35-310,03$ \\
\hline 2 & 6-8 неделя $(n=50)$ & 233,00 & 237,10 & $141,13-334,43$ \\
\hline 3 & $12-13$ неделя $(n=41)$ & 243,00 & 240,95 & $152,00-323,00$ \\
\hline 4 & $22-24$ неАеля $(n=58)$ & 245,50 & 251,29 & $135,38-393,30$ \\
\hline 5 & 34-36 нелеля $(n=38)$ & 222,00 & 224,11 & $134,90-348,15$ \\
\hline 6 & На 2-3 сутки после родов $(n=31)$ & 227,00 & 254,16 & $159,50-465,25$ \\
\hline
\end{tabular}

патологии гемостаза КГБУЗ «Краевая клиническая больница» (г. Барнаул) при участии сотрудников Алтайского филиала ФГБУ «Гематологический научный центр» Минздрава России, лаборатории гематологии ЦНИЛ ГБОУ ВПО «Алтайский государственный медицинский университет» Минздрава России и лаборатории ООО «Инвитро-Сибирь», г. Новосибирск. В исследование включены беременные и небеременные женщины в возрасте от 18 до 35 лет.

В критерии исключения вошли: возраст младше 18 или старше 35 лет; отягощенный акушерский и гинекологический анамнез; осложненное течение настоящей беременности; отягощенный личный геморрагический или тромботический анамнез; прием комбинированных оральных контрацептивов в течение трех последних месяцев до наступления настоящей беременности; вспомогательные репродуктивные технологии в анамнезе или при настоящей беременности; оперативное родоразрешение в анамнезе или при настоящей беременности; наличие экстрагенитальной патологии, в том числе сахарного диабета, бронхиальной астмы, эндокринной патологии; мезенхимальная дисплазия; протезы клапана сердца и сосудов; острый пиелонефрит, цистит или обострение их хронического течения; злокачественные новообразования, носительство вируса иммунодефицита человека, вирусного гепатита В и (или) $\mathrm{C}$; прием лекарственных препаратов во время настоящей беременности, влияющих на систему гемостаза (антиагреганты, нестероидные противовоспалительные препараты, антикоагулянты); откло- нения в результатах лабораторного обследования: уровень гомоцистеина в сыворотке крови (до беременности) свыше 15 мкМ, гемоглобин выше 140 г/л вне беременности и выше 135 г/л во время беременности, количество тромбоцитов в крови ниже 150 или выше $450 \times$ $10^{9} /$, количество лейкоцитов в крови более $12 \times 10^{9} /$ л; носительство мутаций $F 5$ Лейден $(1691 \mathrm{G}>\mathrm{A})$ и/или $F I I(20210 \mathrm{G}>\mathrm{A})$, редкой гомозиготы MTHFR $(677 \mathrm{C}>\mathrm{T})$, а также трех и более полиморфизмов генов $M T H F R$ $(677 \mathrm{C}>\mathrm{T})$, PAI 1 (-675 5G>4G) фибриногена- $F G B(-455 \mathrm{G}>\mathrm{A})$, рецепторов тромбоцитов $G P$ IIIA $(1565 \mathrm{~T}>\mathrm{C})$ и $G P I A(807 \mathrm{C}>\mathrm{T})$; антифосфолипидный синдром и другие аутоиммунные состояния.

Отобраны следующие контрольные этапы для исследования системы гемостаза, учитывающие «критические» сроки беременности: прегравидарный период, 6-8 недель, 12-13 недель, 22-24 недели, 34-36 недель и 2-3-е сутки после родоразрешения. Все женщины, принятые в исследование, обследовались, как правило, однократно.

Статистическая обработка полученных данных осуществлялась с использованием программ Microsoft Office Excel 2003, Statistica 6.1 и Medcalc 12.2.1. Использовался непараметрический критерий Манна-Уитни для двух независимых групп, а также ранговый коэффициент корреляции Спирмена. Статистически значимыми принимались различия $\mathrm{P}$ $<0,05$. Для показателей каждого теста на разных этапах обследования были рассчитаны: медиана (Ме), среднее значение $(\mathrm{X})$ и референтные интервалы (2,5-97,5\%).

\section{Результаты и обсуждение}

По итогам проведенного исследования подсчет количества тромбоцитов не выявил значимых изменений во время беременности и после родоразрешения (по отношению к небеременным женщинам), см. таблицу, хотя в литературе имеются отличные от этого точки зрения [13, 17-27].

Кроме того, в противовес ряду публикаций [12, 23, 24] не было найдено и заметных изменений определяемой по методике Born [28] агрегации тромбоцитов на протяжении беременности при использовании всей современной панели агонистов агрегации (арахидоновая кислота, аденозиндифосфат - АДФ, адреналин, коллаген) в конечных концентрациях, рекомендованных Британской рабочей группой по гемостазу и тромбозам и Международным обществом по тромбозу и гемостазу (ISTH) [29-38].

В то же время изучение агрегационной функции тромбоцитов у беременных женщин при использовании сверхмалой дозы АДФ (в конечной концентрации 0,1 мкМ) выявило интересные данные, согласно которым тромбоциты беременных женщин в присутствии минидоз динатриевой соли аденозиндифосфата заметно активируются во второй половине беременности (рис. 1).

Повышение чувствительности тромбоцитов к этой дозе АДФ проявляло себя уже с 12-13 недели беременности, а медиана максимального значения агрегации увеличивалась в 1,3-6,4 раза (в сравнении с данными у небеременных женщин), достигая максимума на 4-м этапе обследования (22-24-я неделя).

Ристоцетин-кофакторная активность ФВ возрастала по мере прогрессирования беременности (рис. 2), начиная с 12-13-й недели и увеличивалась по медиане от исходных значений в $1,19(\mathrm{P}<0,008)$ на 22-24й и 1,42 раза $(\mathrm{P}<0,001)$ на $34-36-$-й неделе гестации, оставаясь высокой в первые сутки после родоразрешения $(\mathrm{P}<0,001)$, что соответствует результатам, приведенным Y. Stirling и соавт. [39].

Корреляционная связь между ристоцетин-кофакторной активностью 
ФВ и агрегацией тромбоцитов с АДФ, взятой в «мини дозе», составила 0,17 $(\mathrm{P}=0,02)$.

Помимо активности ФВ, был определен уровень антигена ФВ. В результате было установлено динамичное повышение концентрации этого белка во время беременности от исходного уровня на 21,$5 ; 57 ; 88$ и $158 \%$ (по медиане) соответственно на втором, третьем, четвертом и пятом этапах обследования. Максимальные значения данного показателя были зафиксированы на 2-3 сутки после родоразрешения с верхним пределом допустимых значений на уровне $291 \%$. Определен достаточно высокий коэффициент корреляции между антигеном и активностью ФВ в плазме крови беременных женщин, который составил 0,43 (P <0,001), что в целом соответствует ранее опубликованным данным [4, 13, 15, 39, 40].

Предполагается, что повышение уровня ФВ при беременности связано с гиперэстрогенемией и активацией его синтеза эндотелием кровеносных сосудов $[15,23,41]$ и ассоциируется с проявлениями эндотелиальной дисфункции при преэклампсии [42]. Последний представляет собой сложный мультимерный адгезивный гликопротеин (в мономерной форме 280 кДа), синтезируемый эндотелиальными клетками и мегакариоцитами $[43,44]$, имеет домены связывания с гликопротеиновыми рецепторами тромбоцитов (GPIb и IIb/IIIa), коллагеном, гепарином и VIII фактором свертывания крови, опосредует адгезию тромбоцитов к субэндотелию через взаимодействие с рецептором тромбоцитов гликопротеином $\mathrm{Ib}$ $[45,46]$. Крупные мультимеры ФВ расщепляются металлопротеиназой ADAMTS-13 в процессе их секреции из эндотелиальных клеток под влиянием провоспалительных цитокинов, включая фактор некроза опухоли, интерлейкина-8 и интерлейкина-6 [41]. Необычно крупные мультимеры ФВ при низкой активности этого фермента инициируют активацию тромбоцитов и способны привести к тотальной тромбоцитопении и множественному образованию гиалиновых (тромбоцитарных) тромбов

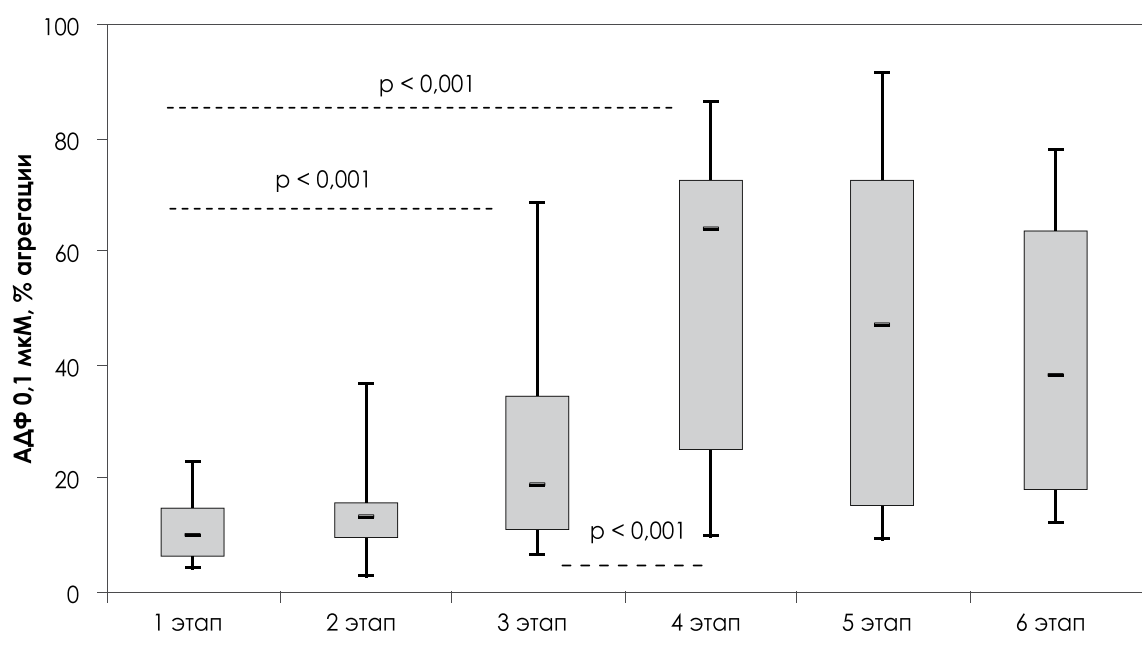

Рисунок 1. Аинамика агрегации тромбоцитов с ААФ, взятой в конечной концентрации 0,1 мкМ. Примечание: здесь и в Аругих рисунках медиана - горизонтальная разАеляющая миния внутри прямоугольника; 50\% полученных значений - прямоугольник, заполненный серым цветом: значения, соответствующие 2,5 и 97,5 перцентилю - нижний и верхний вертикальные бары.

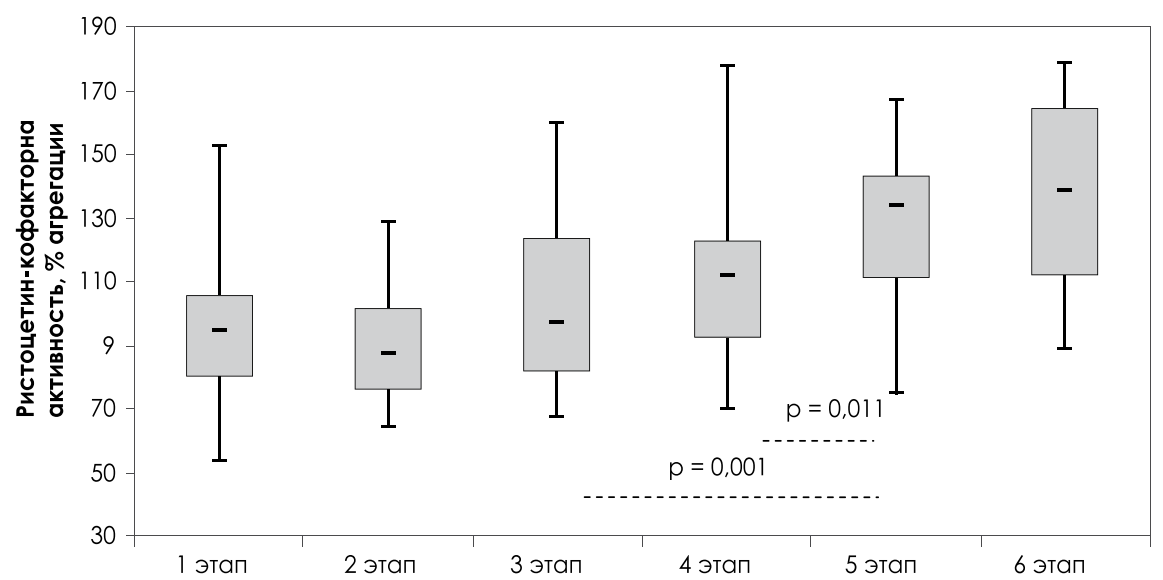

Рисунок 2. Аинамика ристомицин-кофакторной активности ФВ.

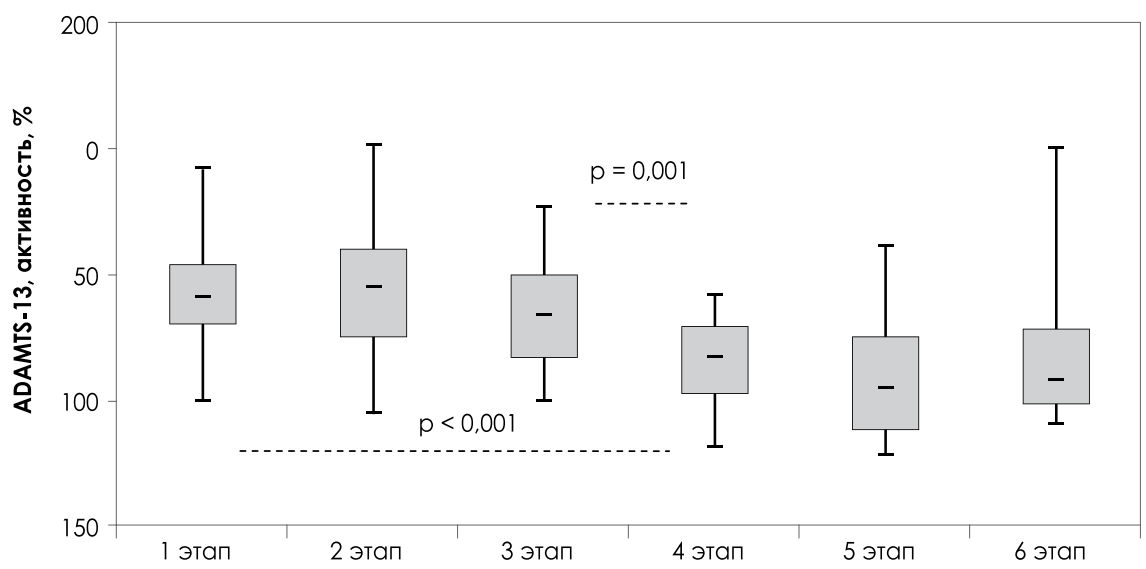

Рисунок 3. Аинамика активности метал^опротеиназы ADAMTS-13 в плазме крови.

в микрососудах при тромботической тромбоцито-пенической пурпуре, ТТП $[43,47]$. Такая ситуация может возникнуть при наследственном дефиците секреции ADAMTS-13 или его сниженной активности, вызванной генными мутациями или вследствие приобретенных дефектов активности ADAMTS-13, обусловленных аутоантителами [43, 48]. Работ по сравнительному изучению ADAMTS-13 и содержания антигена ФВ при физиологической беременности крайне мало [49-50]. 
Нами был проведен анализ динамики активности (рис. 3) и содержания металлопротеиназы ADAMTS-13 в плазме крови беременных и небеременных женщин.

В результате был установлен достаточно стабильный уровень активности и антигена фермента ADAMTS-13 в интервале с 6-й по 13-ю неделю беременности, сравнимый по величине с величиной соответствующих показателей, установленных у небеременных женщин. Начиная с 22-й недели до поздних сроков гестации, а также в ближайшие дни после родоразрешения наблюдалось заметное снижение уровня данного фермента: по активности на 26,4-39,2 \% и по антигену на $28,7-$ $31,7 \%$, по сравнению с данными вне беременности.

Определена положительная корреляционная связь между антигеном и активностью металлопротеиназы ADAMTS-13 в плазме крови ( $r=0,41$; $P<0,001)$.

Активность ФВ во время беременности находится в обратной связи с функциональной активностью металлопротеиназы ADAMTS-13, выделяемой эндотелием кровеносных сосудов и расщепляющей ФВ. У женщин во время физиологически протекающей беременности и сразу после родов коэффициент корреляции между активностью ФВ и активностью фермента ADAMTS-13 составил $-0,27$ (P < 0,001), а между антигенами ФВ и металлопротеиназы ADAMTS-13 был равен -0,32 $(\mathrm{P}<0,001)$.

Ни повышения ПФ-4, ни увеличения в крови беременных женщин маркеров повреждения сосудистой стенки эндотелина-1 и тромбомодулина (CD 141), в сравнении с данными у небеременных женщин, нами найдено не было в отличие от опубликованных данных других авторов [51].

\section{Заключение}

В настоящем исследовании предпринята попытка изучить динамику содержания и активности большинства участников гемостатических реакций, выполняющих свою роль в микроциркуляторном русле в разные сроки физиологи- ческой беременности. В ходе работы выявлен феномен повышенного ответа тромбоцитов на минидозы агониста агрегации АДФ (в финальной концентрации 0,1 мкМ), начиная с 12-13 недели с максимумом эффекта на 22-24 неделе беременности. При этом использование рекомендованных международным сообществом высоких доз индукторов агрегации тромбоцитов (арахидоновая кислота, АДФ, адреналин, коллаген) оказалось неинформативным с точки зрения оценки активации этих клеток.

По мере развития беременности отмечено значительное увеличение уровня и активности ФВ, что находилось в прямой корреляционной связи с повышенным ответом тромбоцитов на мини дозы АДФ. Эти отклонения не сопровождались дегрануляцией тромбоцитов, о чем свидетельствовал стабильно низкий уровень ПФ-4 на всех этапах исследования.

Нарастание активности ФВ, сочетающееся со снижением активности фермента ADAMTS-13, достигало максимума в конце сроков гестации, что рассматривается нами как один из защитных механизмов от повышенной кровопотери в родах, но в то же время создающий риск возникновения артериальных и венозных тромбозов.

Несмотря на то что гиперпродукция ФВ традиционно считается проявлением эндотелиоза, мы не нашли повышение уровней других классических маркеров этого процесса эндотелина-1 и свободного тромбомодулина, что ставит под сомнение наличие эндотелиальной дисфункции при физиологически протекающей беременности.

Субпороговая активация тромбоцитов наряду с увеличением активности ФВ при сниженной активности ADAMTS-13 являются предпосылками для уменьшения кровопотери в родах, но при условии наличия дополнительных факторов тромбогенного риска (переношенная или многоплодная беременность, аномалии родовой деятельности и др.) создают угрозу формирования тромбоэмболического синдрома.
Полагаем, что полученные нами референтные диапазоны показателей сосудисто-тромбоцитарного гемостаза на разных сроках физиологически протекающей беременности могут являться ориентиром для разграничения нормы и патологии, дифференциальной диагностики нарушений свертываемости крови и формирования групп риска по кровотечениям и тромбозам.

В следующих публикациях в рамках поднятой темы мы остановимся на результатах оценки динамики и взаимосвязи других участников гемостатических реакций на протяжении беременности - коагуляционного и антикоагулянтного звеньев системы гемостаза, системы фибринолиза, приведем данные анализа маркеров тромбинемии и показателей современных интегральных методов исследования: теста генерации тромбина и тромбоэластометрии.

\section{Список ^итературы}

1. Brenner, B. Haemostatic changes in pregnancy / B. Brenner // Thromb Res. - 2004.Vol. 114, № 5-6.- P. 409-414.

2. Franchini, M. Haemostasis and pregnancy / M. Franchini // Thromb Haemost. - 2006 Mar. - Vol. 95, № 3.-P. 401-413.

3. Hellgren, M. Hemostasis during normal pregnancy and puerperium / M. Hellgren // Semin Thromb Hemost. - 2003. - Vol. 29.- P. 125-130.

4. O'Riordan, M. N. Haemostasis in normal and abnormal pregnancy / M.N. O'Riordan, J. R. Higgins // Best Pract Res Clin Obstet Gynaecol.-2003 Jun. - Vol. 17, № 3.-P. 385-396.

5. Классиорикация, молекулярные механизмы и новые методы Аиагностики тромбофилий / 3. С. Баркаган А. П. Цывкина, Г.И. Костюченко Г.И. и Ар. // Бюметень Сибирского отАеления PAMH. - 2002. - № 104 (2).- C.51-55.

6. Thornton, P. Coagulation in pregnancy / P. Thornton, J. Douglas // Best Pract Res Clin Obstet Gynaecol._-2010 Jun._- Vol. 24, № 3.- P. 339-352.

7. Hematocrit and risk of venous thromboembolism in a general population. The Tromso study / SK. Braekkan, EB. Mathiesen, I. Njølstad et al. // Haematologica. - 2010 Feb.Vol. 95, № 2.-P. 270-275.

8. Prevention of venosus thromboembolism: The Seventh ACCP Conference on Antithrombotic Therapy and Thrombolytic Therapy / W. Geerts, G. Pineo, J. Heit et al. // Chest.-2004 Sep. - Vol. 126, № 3.P. 338S-400S.

9. Момот, А. П. Фармакотерапия массивных акушерских кровотечений / А.П. Момот И.В. Молчанова, В.Б. Цхай // Акушерство и гинекология.- 2010.- № 4.- С. 3-10. 
10. Фелорова, Т. А. Анализ многоцентрового применения рекомбинантного коагуляционного фоктора VII (НовоСэвен в лечении массивных акушерс-ких кровотечений / Т. А. Федорова, Е.В. Стрельникова, О.В. Рогачевский // Акушерство и гинекология. - 2008. - № 4.- С. 48-52.

11. Pharmacotherapy of Massive Obstetric bleedings as Alternative to hysterectomy / A. Momot, I. Molchanova, V. Tskhai etal. // Hysterectomy / e by Ayman Al-Hendy, Mohamed Sabry. - Croatia: Intech, 2012.P.197-222.

12. Бышевский, А.Ш. Гемостаз при оризиологической беременности, беременности с артериальной гипертензией и преэклампсией / А.Ш. Бышевский, В. А. Полякова, А.Ю. РУАзевич // Тромбо3, гемостаз и реология. - 2010. - № 4 (44).- C. 13-30.

13. Abbassi-Ghanavati, M. Pregnancy and laboratory studies: a reference table for clinicians / M. Abbassi-Ghanavati, L. G. Greer, F. G. Cunningham // Obstet Gynecol. 2009 Dec. - Vol. 114, № 6.-P. 1326-1331.

14. Laboratory reference intervals during pregnancy, delivery and the early postpartum period / A. Klajnbard, P. B. Szecsi, N.P. Colov et al. // Clin Chem Lab Med. - 2010 Feb. Vol. 48, № 2.-P. 237-248.

15. Ramsay, M. Normal hematological changes during pregnancy and the puerperium / M. Ramsay // The Obstetric Hematology Manual / ed by S. Pavord, B. Hunt.- New York: Cambridge University Press, 2010.-P. 3-12.

16. Haemostatic reference intervals in pregnancy / P. B. Szecsi, M. Jǿrgensen, A. Klajnbard et al. // Thromb Haemost. - 2010 Apr. - Vol. 103, № 4.- P. 718-727.

17. Макацария, А.А. Вопросы циркуляторной аАаптации системы гемос-таза при фои зиологической беременности и синАром Аиссеминированного внутрисосуАистого свертывания / А.А. Макацария, А.А. Мищенко // Акушерство и гинекология.1997.- № 1.- С. 38-41.

18. Папаян, А. П. Современное представле ние о механизме регуляции свертывания крови / ^. П. Папаян // Тромбоз, гемостаз и реология. - 2003. - № 2 (14).- С. 7-11.

19. Isermann, B. Relevance of platelets in placental development and function / B. Isermann, P.P. Nawroth // Hamostaseologie. 2007. - Vol. 27, № 4.- P. 263-270.

20. Koelbe, H. Influence of delivery on plasminogen activator inhibitor activity / H. Koelbe, J. Kirchheimer, G. Tatra // J Perinat Med.1989. - Vol. 17, № 2.-P. 107-111.

21. Marumoto, Y. Hemorheological studies on platelet counts and size in normal pregnancy and pregnancies with preeclampsia and intrauterine growth retardation / Y. Marumoto, M. Kaibara, T. Murata // Acta Obstet Gynaecol Jap. - 1989. - Vol. 41 , № 9.- P. 1380-1381.

22. Platelet functions before, during and aft er labor / A. Sagi, D. Creater, J. Goldman et al. // Acta Haematol._ 1981.-Vol. 65, № 1.-P. 67-70.

23. Состояние сосудисто-тромбоцитарного гемостаза при фоииологической беременности и беременности, осложненной гестозом / Н.Г. Белова, А. А. Агаркова,
В.В. УАут и Ар. // Сибирский меАицинский журнал. - 2010.- T. 25, № 4.- выпуск 2.- C. 63-65.

24. Вереина, Н.К. Аинамика показателей гемостаза при фоизиологически протекающей беременности / Н. К. Вереина, С.П. Синицын, В.С. Чулков // КАиническая лабораторная Аиагностика. - 2012. № 2.- C. 43-45.

25. Силельникова, В. М. Невынашивание беременности: руководство Аля практикующих врачей / В.М. Сидельникова, Г.Т. Сухих - М.: ООО «МеАицинское информационное агентство», 2010.-536 с.

26. Fenton, $V$. The platelet count in pregnancy/ V. Fenton, K. Saunders, J. Cavill // J Clin Pathol.- 1977. - Vol. 30, № 1.- P. 68-69.

27. Prisco, D. Hemostatic changes in normal pregnancy / D. Prisco, G. Cluti, M. Falciani // Haematologica reports. - 2005. - Vol. I, № 10.-P. 1-5.

28. Born, GV. Aggregation of blood platelets by adenosine diphosphate and its reversal / GV. Born // Nature.- 1962. - Vol. 194.-P. 927-929.

29. Guidelines on platelet function testing. The British Society for Haematology BCSH Haemostasis and Thrombosis Task Force // J Clin Pathol. - 1988. - Vol. 41.- P. 1322-1330.

30. British Committee for Standards in Haematology. Guidelines for the laboratory investigation of heritable disorders of platelet function / P. Harrison, I. Mackie, A. Mumford et al. // Br J Haematol. - 201 1.- Vol. 155, № 1.- - P. 30-44.

31. Clinical and Laboratory Standards Institute (CLSI). Platelet Function Testing by Aggregometry; Approved Guideline. CLSI document H-58-A (ISBN 1-56238-683-2). USA, 2008.

32. Серов, В.П. Тромботические и геморрагические осложнения в акушерстве / В.П. Серов, А.А. Макацария.- М.: Мелицина, 1987.- 288 с.

33. Шитикова, А.С. Тромбоцитарный гемостаз / А. С. Шитикова.-СПб.: ИзАательство СПб ГМУ, 2000.- 227 c.

34. Murata, M. Platelet function during pregnancy, labor, early puerperium, and in preeclacmpsia / M. Murata // Acta Obstet Gynecol Jap. - 1983. - Vol. 35, № 6.-P. 773-781.

35. Modulatio of neutrophil functions by activated platelet releade factors / S. Spisani, A. L. Giuliani, T. E. Cavalletti et al. // Inflammation. - 1992.—Vol. 16, № 2.P. 147-158.

36. А^яутАина, О.С. Значение исследования системы гемостаза при неосложненном течении беременности и прогнозировании тромбо-геморрагических осложнений / О.С. А^яутАина, А.М. Смирнова, С.Г. Брагинская // Акушерство и гинеко^огия.- 1999. - № 2.- С. 18-23.

37. Kornecki, E. Diminished responsiveness of human platelets to platelet-activating factor during pregnancy / E. Kornecki, Y.H. Ehrlich // Am J Physiol. - 1990. - Vol. 259, № 3 (P+ 2).-P. 766-771.

38. Maternal and fetal platelet activation in normal pregnancy / U. Nicolini, D. Guarneri, G. A. Gianotti et al. // Obstet Gynecol. 1994. - Vol. 83, № 1.- P. 65-69.
39. Haemostasis in normal pregnancy / Y. Stirling, L. Woolf, W.R.S. North et al. // Thromb Haemost. - 1984 Oct 31.-Vol. 52, № 2.-P. 176-182.

40. Bremme, K. A. Haemostatic changes in pregnancy / K. A. Bremme // Best Pract Res Clin Haematol. - 2003 Jun. - Vol. 16, № 2.- P. 153-168.

41. Effects of inflammatory cytokines on the release and cleavage of the endothelial cell-derived ultra-large von Willebrand factor multimers under flow / A. Bernardo, C. Ball, L. Nolasco et al. // Blood.-2004 Jul 1.- Vol. 104, № 1.- - P. 100-106.

42. Фалеева, Н.И. Фактор Вимлебранда как маркер эндотелиальной Аисорункции у беременных женщин с гестозом и роАившихся У них новорожАенных / Н.И. Фалеева, А. В. Суворова, О.М. Малюга // Сибирский меАицинский журнал.-2001.- № 1.- С. 28-32.

43. Moake, J. L. Thrombotic thrombocytopenic purpura / J. L. Moake // Consultative Hemostasis and Thrombosis / ed by C.S. Kithens, B. M. Alving, C. M. Kessler. - 2nd ed.Philadelphia: Saunders Elsevier, 2007.-P. 405-417.

44. Ruggeri, Z.M. Developing basic and clinical research on von Willebrand factor and von Willebrand disease / Z. M. Ruggeri // Thromb Haemost.- 2000 Aug. - Vol. 84, № 2. - P. 147-149.

45. Ultralarge multimers of von Willebrand factor form spontaneous high-strength bonds with the platelet glycoprotein Ib-IX complex: studies using optical tweezers / M. Arya, B. Anvari, G. M. Romo et al. // Blood. -2002 Jun 1. - Vol. 99, № 11.- P. 3971-3977.

46. Shear-induced platelet aggregation can be mediated by $\checkmark W F$ released from platelets as well as by exogenous large or unusually large vWF multimers, requires adenosine diphosphate, and is resistant to aspirin / J.L. Moake, N. A. Turner, N. A. Stathopoulos et al. // Blood.- 1988 May. - Vol. 71, № 5.P. 1366-1374.

47. Practical hemostasis and thrombosis / ed by N. Key, D. O'Shaughnessy, D. Lillicrap.-2nd ed.- Oxford: Wiley Blackwell Publishing Ltd, 2009. - $311 \mathrm{p}$.

48. Recent advances in thrombotic thrombocytopenic purpura / J.E. Sadler, J. L. Moake, T. Miyata et al. // Hematology Am Soc Hematol Educ Program. - 2004. - Vol. 1.- P. 407-423.

49. von Willebrand factor-cleaving protease (ADAMTS13) activity in normal non-pregnant women, pregnant and post-delivery women / A. Sánchez-Luceros, C.E. Farías, M. M. Amaral et al. // Thromb Haemost. 2004 Dec. - Vol. 92, № 6.- - P. 1320-1326.

50. Changes in health and disease of metalloprotease that cleaves von Willebrand factor / P. M. Mannucci, M. T. Canciani, I. Forza et al. / Blood.-2001 Nov 1.- Vol. 98, № 9.P. 2730-2735.

51. Ранние маркеры гестоза и залержки роста п^оАа / В.И. Орлов, 3. С. Крымшокалова, А.М. Мак^юк и Ар. // Вестник РУАН. Серия: меАицина, акушерство и гинекология.-2009.—№ 7.-С. 21-25. 